\title{
Surveillance for anaemia: risk factors in patterns of milk intake
}

\author{
A F Mills
}

\begin{abstract}
The association between patterns of milk intake and anaemia was studied during a surveillance programme for iron deficiency anaemia. Children aged 8-24 months were examined when they attended a routine immunisation clinic. Haemoglobin was measured on finger prick blood samples using a portable haemoglobinometer, and a dietary questionnaire was completed, with special emphasis on the type and volume of milk intake and the age at which whole cows' milk was introduced.

Anaemia (defined as a haemoglobin concentration of $<110 \mathrm{~g} / \mathrm{l}$ ) was diagnosed in 33 children (22\%) and was more common among children who were not white. Continued feeding with breast milk and the early introduction of whole cows' milk were associated with a significantly higher prevalence of anaemia. No child taking formula milk was anaemic. Asian children drank significantly more milk a day than other groups, but there was no correlation between daily milk intake and haemoglobin concentration.
\end{abstract}

Iron deficiency anaemia is one of the most common deficiency diseases in children in developed countries. It affects particularly those living in poor socioeconomic circumstances, and children of immigrant communities-for example, those from Asian communities are commonly affected. ${ }^{12}$ The deficiency is in most cases of dietary origin, and probably results from inadequate weaning. Many affected toddlers take diets consisting of starchy solids and large amounts of whole cows' milk, ${ }^{3}$ which reduces their intake of iron containing foods. A further factor may be that gastrointestinal bleeding may be caused by whole cows' milk when introduced to children under the age of 6 months. ${ }^{4}$ Iron for- tified formula milk is likely to protect against iron deficiency anaemia. ${ }^{5}$ Breast milk contains iron in a highly bioavailable form, and provides the infant's iron requirements for the first six months. ${ }^{6}$ If factors such as the type and volume of milk intake can be correlated with the incidence of anaemia, such measurements may be useful in detecting those at particular risk of iron deficiency anaemia.

The aim of this study was to survey the type and volume of milk intake, and the age at which whole cows' milk was introduced into the diets of children aged 8-24 months, and to examine the association between these factors and the prevalence of anaemia.

\section{Patients and methods}

A programme to screen toddlers for anaemia was set up in Waltham Forest Health Authority in east London, with the aim of screening all children aged 8-24 months attending one of five routine immunisation clinics for their third diphtheria, pertussis, and tetanus, or measles, immunisation between December 1987 and March 1988. All the clinics were grouped in a small area in the south of Waltham Forest in which a large proportion of the families are first or second generation immigrants. The parents were approached when they attended the immunisation clinic and were given a written and verbal description of the programme. The written description was available in English, Urdu, Bengali, Gujarati, and Punjabi. An interpreter was always available. If parents agreed, they gave written consent and their child was seen immediately after the immunisation. Siblings of the children were also seen if the parents wished, but were not included in this study. The programme was in two parts.

Firstly, a questionnaire was completed by the doctor, and details of parents' racial group,

\section{Department of Community Paediatrics, Waltham Forest Health Authority \\ Correspondence to: Dr A F Mills, Islington Health Authority, Insurance House, Insurance Street, London WC1X 0JB.}

Accepted 4 December 1989
Table 1 Details of 148 children studied

\begin{tabular}{|c|c|c|c|c|}
\hline $\begin{array}{l}\text { Ethnic } \\
\text { group }\end{array}$ & $\begin{array}{l}\text { Total No } \\
\text { of } \\
\text { children }\end{array}$ & $\begin{array}{l}\text { Mean }(S D) \\
\text { haemoglobin } \\
\text { concentration } \\
(\mathrm{g} / \mathrm{l})\end{array}$ & $\begin{array}{l}\text { No (\%) of } \\
\text { children } \\
\text { anaemic }\end{array}$ & $\begin{array}{l}\text { Mean (SD) } \\
\text { milk intake } \\
\text { (mli24hours) }\end{array}$ \\
\hline $\begin{array}{l}\text { White } \\
\text { Asian: } \\
\text { Pakistani } \\
\text { Bangladeshi } \\
\text { Indian }\end{array}$ & $\begin{array}{r}52 \\
62 \\
48 \\
2 \\
12\end{array}$ & $\begin{array}{l}119 \cdot 9(9 \cdot 3) \\
116 \cdot 2(10 \cdot 9)\end{array}$ & $\begin{array}{r}9(17) \\
16(26)\end{array}$ & $\begin{array}{l}496(248) \\
740(307)\end{array}$ \\
\hline $\begin{array}{l}\text { Other: } \\
\text { Caribbean } \\
\text { West African } \\
\text { Southeast Asian and Chinese } \\
\text { Mixed race }\end{array}$ & $\begin{array}{r}34 \\
18 \\
5 \\
5 \\
6\end{array}$ & $115 \cdot 1(9 \cdot 3)$ & $6(18)$ & $548(289)$ \\
\hline
\end{tabular}


Table 2 Number taking each milk type related to age in each racial group

\begin{tabular}{|c|c|c|c|c|c|c|c|c|c|c|c|c|}
\hline & \multicolumn{4}{|c|}{ White: age range (months) } & \multicolumn{4}{|c|}{ Asian: age range (months) } & \multicolumn{4}{|c|}{ Other: age range (months) } \\
\hline & $8-11$ & $12-14$ & $15-17$ & $18-24$ & $8-11$ & $12-14$ & $15-17$ & $18-24$ & $8-11$ & $12-14$ & $15-17$ & $18-24$ \\
\hline $\begin{array}{l}\text { Breast milk } \\
\text { Formula milk } \\
\text { Whole cows' milk }\end{array}$ & $\begin{array}{l}1 \\
2 \\
9\end{array}$ & $\begin{array}{l}1 \\
2 \\
9\end{array}$ & $\begin{array}{r}1 \\
1 \\
21\end{array}$ & $\begin{array}{l}0 \\
0 \\
5\end{array}$ & $\begin{array}{r}1 \\
3 \\
14\end{array}$ & $\begin{array}{r}2 \\
0 \\
14\end{array}$ & $\begin{array}{r}1 \\
0 \\
16\end{array}$ & $\begin{array}{r}0 \\
0 \\
10\end{array}$ & $\begin{array}{l}3 \\
1 \\
2\end{array}$ & $\begin{array}{l}0 \\
1 \\
6\end{array}$ & $\begin{array}{r}0 \\
5 \\
10\end{array}$ & $\begin{array}{l}0 \\
0 \\
6\end{array}$ \\
\hline
\end{tabular}

One Asian child (previously having had whole cows' milk) was taking no milk at time of study.

Table 3 Age (months) when whole cows' milk was introduced

\begin{tabular}{lccc}
\hline & \multicolumn{3}{l}{ No (\%) taking whole cows' milk } \\
\cline { 2 - 4 } Age (months) & $\begin{array}{l}\text { White } \\
(n=39)\end{array}$ & $\begin{array}{l}\text { Asian } \\
(n=50)\end{array}$ & $\begin{array}{l}\text { Other } \\
(n=22)\end{array}$ \\
\hline 4 & $1(3)$ & $2(4)$ & $1(5)$ \\
6 & $8(21)$ & $16(32)$ & $6(27)$ \\
8 & $21(54)$ & $30(60)$ & $11(50)$ \\
10 & $27(69)$ & $39(78)$ & $13(59)$ \\
12 & $30(77)$ & $42(84)$ & $16(73)$
\end{tabular}

Eleven mothers could not remember when whole cows' milk was introduced. Twenty five were on other milks, and one child was taking no milk.

child's age, type and daily average volume of milk intake, and age at which whole cows' milk was introduced were recorded. If more than one type of milk was being taken, the milk that predominated was noted. Any personal or family history of anaemia was recorded and any courses of oral iron were recorded. An informal assessment of diet was also undertaken. Parents were questioned about the amount of meat, vegetables, sources of vitamin $C$, starchy foods, sweets, and crisps their child ate during an average day.
All children were classified into one of three racial groups: white (European), Asian (from the Indian subcontinent), and others (AfroCaribbean, south east Asia and Chinese, and mixed race). Most of the Asian children came from Moslem families originating from Pakistan.

Secondly, a finger prick blood sample was taken, and the haemoglobin concentration was measured using a 'HemoCue' haemoglobinometer (Clandon Scientific). ${ }^{7}$ Further capillary blood was collected into a bottle containing EDTA for subsequent analysis if indicated.

Those found to be anaemic (defined as a haemoglobin concentration of $<110 \mathrm{~g} / \mathrm{l})^{8}$ were referred to a paediatric clinic for further investigation and treatment. Those who were considered to be having an inadequate diet, despite the haemoglobin concentration being $>110 \mathrm{~g} / \mathrm{l}$, were given nutritional counselling and followed up in the community clinic.

We tried to screen all eligible children. Of those offered the test, $65 \%$ agreed immediately. Some returned on a subsequent day. Common reasons for refusal were that parents felt that a
Figure 1 Haemoglobin concentrations for each type of milk taken. The horizontal bars indicate the mean. Those on whole cows' milk are separated into the age groups at which it was first introduced. Mean (SD) haemoglobin concentrations: breast milk $107 \cdot 8(13)$; formula milk $122 \cdot 4(8 \cdot 8)$; and whole cows' milk $117(9 \cdot 5)$.

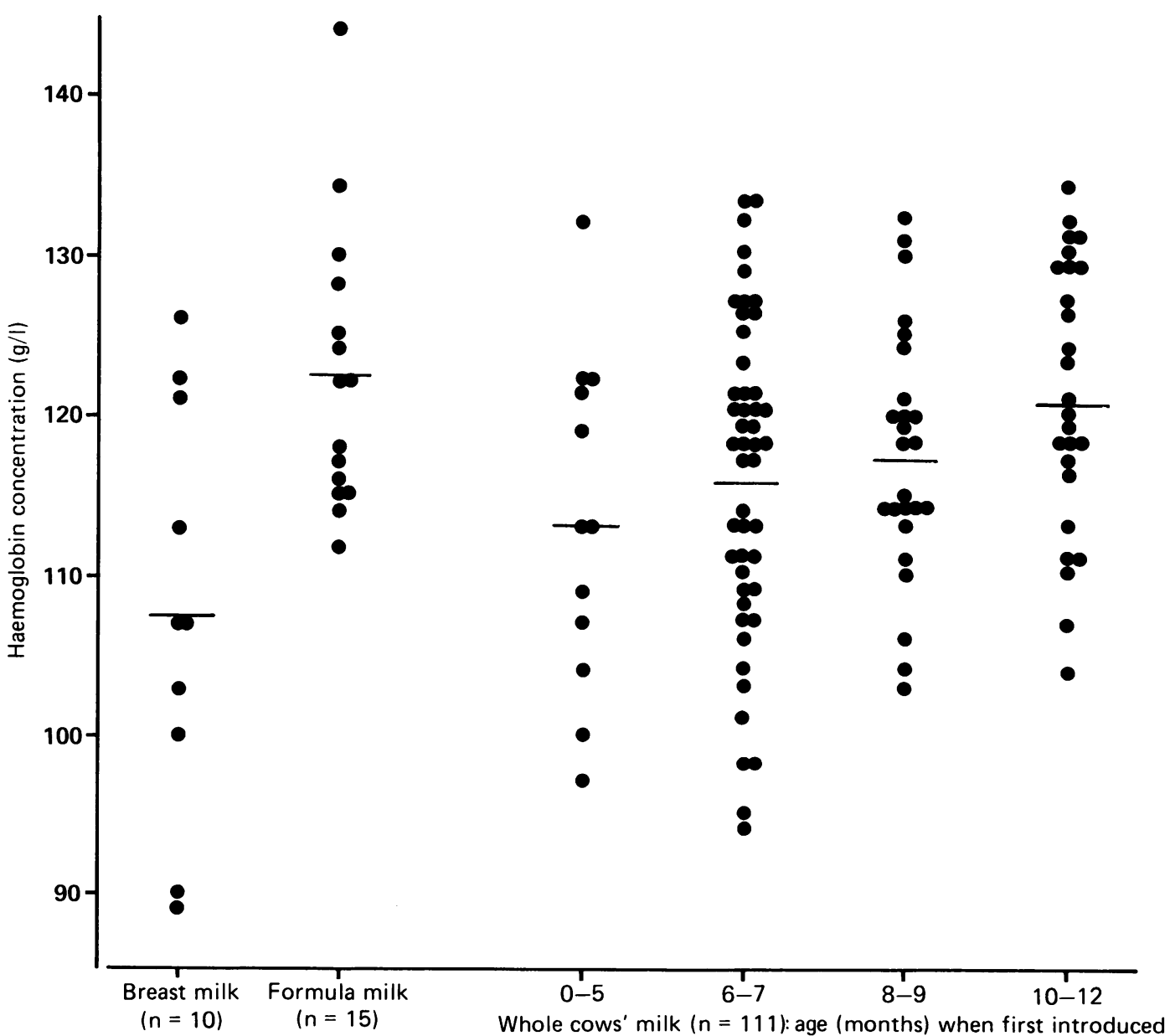


further painful procedure after immunisation was unfair and others felt that their children were unlikely to be anaemic.

Statistical evaluation was by unpaired Student's $t$ test and $\chi^{2}$ with Yates's correction. Ethics committee approval was obtained.

\section{Results}

A total of 150 parents gave consent for their children to take part in the scheme. Two children were subsequently found to have $\beta$ thalassemia trait and were excluded from the study. There were 73 boys and 75 girls. Table 1 shows the mean haemoglobin concentrations and mean daily volumes of fresh or formula milk in each racial group. Asian children drank significantly more milk than both white children $(p<0.001)$ and those from other groups $(p<0 \cdot 01)$. The white children had a slightly higher mean haemoglobin concentration and a lower prevalence of anaemia than the other two groups, but these are not statistically significant.

Table 2 shows the age distribution and main type of milk being taken at the time of screening according to age in each group. All children over 18 months mostly drank cows' milk. Table 3 shows the age at which children had first been given fresh cows' milk; 11 mothers could not remember this age. The mean (SD) haemoglobin from these 11 children was $115.5 \mathrm{~g} / 1(10 \cdot 3)$.

Figure 1 shows the association between the type of milk taken and haemoglobin concentration. The children taking formula milk had a significantly higher mean haemoglobin concentration than those taking whole cows' milk $(p<0.05)$, or breast milk $(p<0.01)$. No child taking formula milk was anaemic. The association between the age at which fresh cows' milk was started and haemoglobin concentration is shown. Mean haemoglobin concentration rose with increasing age of introduction of whole cows' milk. Anaemia was significantly more common among those starting whole cows' milk before the age of 8 months compared with those starting after this age. $\left(\chi^{2}=5.67 \mathrm{p}<0.05\right)$.

Figure 2 shows the association between the volume of milk taken during each 24 hours and haemoglobin concentration. The greater volume of milk taken by Asian children is shown. There was no correlation between the daily milk intake and haemoglobin concentration, although anaemia was more common in Asians who drank more than a litre a day compared with those who drank less; this was, however, not statistically significant.

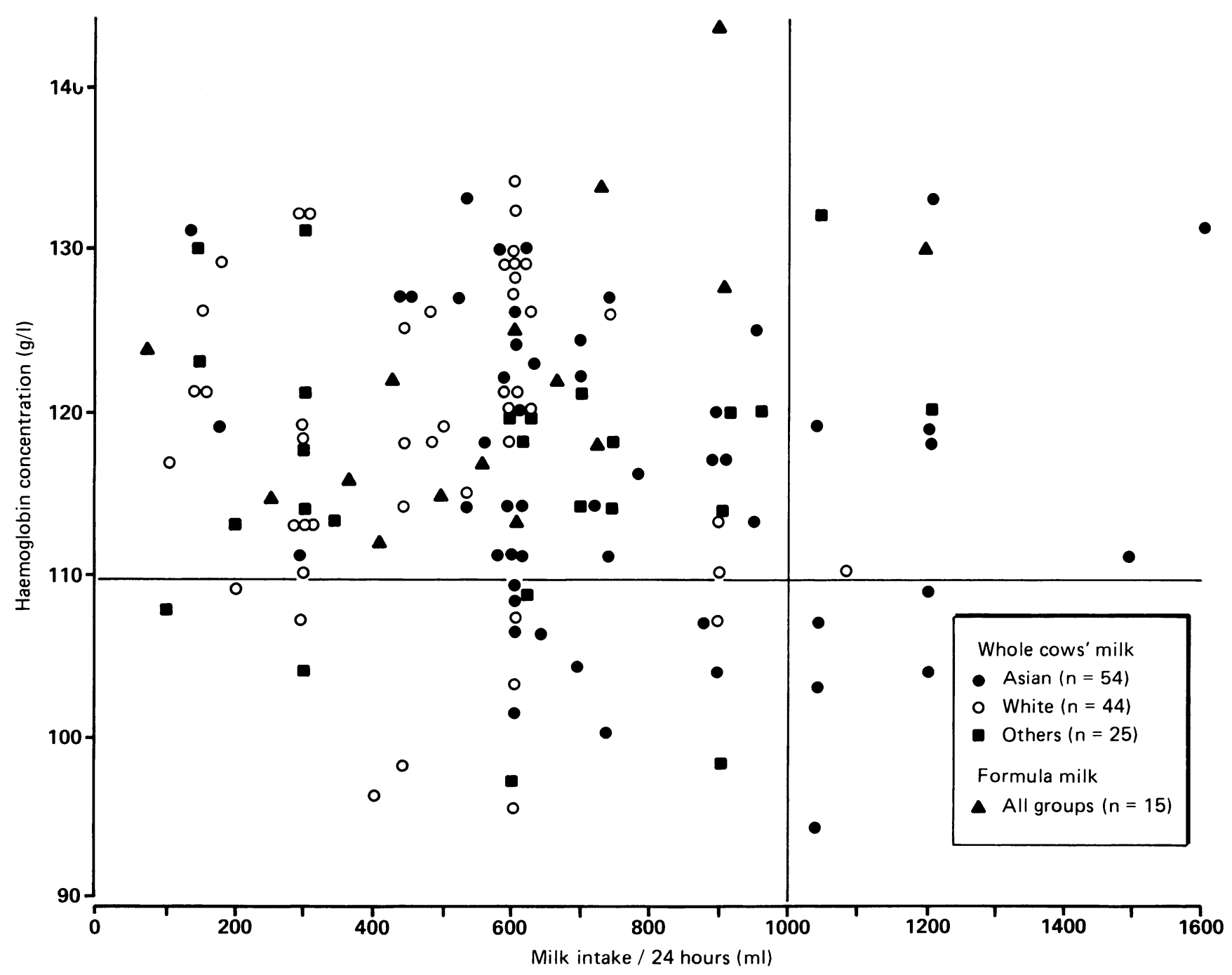

Figure 2 Association between volume of milk taken/24 hours and haemoglobin concentration by racial group. Ten children were receiving breast milk at the time of the study and are not included. 


\section{Discussion}

Whether there is a need for a comprehensive screening campaign for iron deficiency anaemia is controversial. ${ }^{9}$ The finding that cognitive development of affected toddlers may be slowed has led some to advocate for a programme in groups that are at risk. ${ }^{10}$

The results of this study show that surveillance for iron deficiency anaemia using a routine finger prick sample is possible in a community paediatric clinic. Anaemia was found in $22 \%$ of our patients, and there was a higher prevalence among the non-white population. This is similar to results from Bradford and Birmingham. ${ }^{110}$ The use of haemoglobin concentration to select those likely to be iron deficient means that a number of false negatives will occur. The surveillance programme did, however, include informal dietary assessment with counselling, and follow up for those taking a poor diet. This aspect of the programme helped to ensure that children with false negative results on blood testing at least had careful attention paid to their diets.

The age of the group studied was well above the age when weaning and the introduction of solids containing iron usually takes place. To detect those at risk of iron deficiency it is more logical to undertake a formal dietary assessment and analysis. This is, however, a skilled and time consuming process and is not suitable as a screening procedure. This study aimed to look at simple and easily assessed dietary measurements.

The higher mean concentration of haemoglobin in formula fed infants is presumably because of the iron fortification in these milks. This observation has been made previously, but is important. ${ }^{11}$ Prolonging formula feeding may be good advice to those parents who have difficulty in establishing their infants on mixed feeding.

The significantly lower haemoglobin concentration among those who were breast fed is interesting. The amount of iron in breast milk, although low, is extremely well absorbed and breast feeding is said to protect against iron deficiency anaemia in the first 6 months. ${ }^{12}$ Over this age, however, some form of additional iron intake is required in order to replace depleted iron stores. More information is needed about the success of weaning these infants, as this may remain a problem associated with prolonged breast feeding.

Early introduction of cows' milk predisposes to iron deficiency. ${ }^{4}$ Cows' milk is a poor source of iron and it may cause gastrointestinal bleeding, particularly in the immature gut. This may explain the rise in mean haemoglobin concentration with increasing age when whole cows' milk was first introduced. Other factors may include the length of time for which formula milk was given before changing to cows' milk, and the quality of weaning solids given to those who started cows' milk at an early age.

Clinical experience indicates that those with iron deficiency anaemia often drink large volumes of milk. There was no clear correlation between the quantity of milk and the haemoglobin concentration, although anaemia is more common among those drinking over a litre of milk a day. Presumably a large milk intake does not necessarily result in an iron deficient diet.

The results of this study show that routine finger prick samples are practicable for use in a community clinic. Anaemia is common, and is usually caused by iron deficiency. Prolonged breast feeding and early introduction of cows' milk are associated with anaemia, and the continued use of formula milk protects against anaemia.

No account was taken in this study of the role of birth weight, or the age and quality of weaning. More detailed information is required from a prospective study. In the meantime early introduction of whole cows' milk should be discouraged, and good weaning practices (including introducing mixed solids and vitamin $\mathrm{C}$ ) should be promoted. Formula milk should be continued up to the age of 1 year-and possibly beyond-for those children that are not well established on a good mixed diet. Those that continue to breast feed after 6 months should have particular attention paid to weaning. Screening for iron deficiency should be considered in those areas with large immigrant populations.

I thank Dr P Thompson, Dr N Meadows, Mrs M Slevin and the clinic administrators, and Dr C D'Silva and the staff of the haematology department, Whipps Cross Hospital.

1 Ehrhardt P. Iron deficiency in young Bradford children from different ethnic groups. Br Med $\mathcal{f} 1986 ; 292: 90-3$.

2 Grindulis H, Scott PH, Belton NR, Wharton BA. Combined deficiency of iron and vitamin $\mathrm{D}$ in Asian toddlers. Arch Dis deficiency of iron and
Child $1986 ; 61: 843-8$

3 Jivani SKM. The practice of infant feeding among Asian immigrants. Arch Dis Child 1978;53:69-73.

4 Sadowitz PD, Oski FA. Iron status and infant feeding practices in an urban ambulatory center. Pediatrics 1983;72: 33-6.

5 Marsh A, Long H, Stierwalt E. Comparative hematological response to iron fortification of a milk formula for infants. Pediatrics 1959;24:404-12.

6 American Academy of Pediatrics Committee on Nutrition: Iron supplementation for infants. Pediatrics 1976;58:765-8.

7 Mills AF, Meadows N. Screening for anaemia: evaluation of a haemoglobinometer. Arch Dis Child 1989;64:1468-71.

8 World Health Organisation. Nutritional anaemias. WHO Tech Rep Ser 1972; No 503.

9 Hall DMB, ed. Health for all children: report of the foint Working Party on Child Health Surveillance. Oxford: Oxford University Press, 1989.

10 Aukett MA, Parks YA, Scott PH, Wharton BA. Treatment with iron increases weight gain and psychomotor development. Arch Dis Child 1986;61:849-57.

11 Stekel A. Prevention of iron deficiency. In: Stekel A, ed. Iron nutrition in infancy and childhood. New York: Raven Press, 1984:179-94.

12 Saarinen UM. Need for iron supplementation in infants on prolonged breast feeding. $\mathcal{f}$ Pediatr 1978;93:177-80. 